\title{
ANÁLISE DOS RELATÓRIOS SOCIOAMBIENTAIS DA USINA HIDRELÉTRICA DE BELO MONTE A LUZ DA TEORIA DA LEGITIMIDADE
}

\section{ANALYSIS OF THE SOCIO-ENVIRONMENTAL REPORTS OF THE BELO MONTE HYDROELECTRIC POWER PLANT IN THE LIGHT OF THE LEGITIMACY THEORY MAIS SOBRE ANALYSIS}

0 artigo foi aprovado e apresentado na III Conferência Internacional de Gestão de Negócios (CINGEN), realizado de 29/07 a 31/07 de 2019, em Cascavel (PR)

\section{RESUMO}

Este artigo faz uma análise das estratégias de legitimidade propostas por Suchman (1995) na Usina Hidrelétrica de Belo Monte. Caracteriza-se como um estudo de caso, com abordagem quantitativa dos dados e análise documental. Para o alcance do objetivo geral, fez-se uso dos relatórios anuais e socioambientais, dos anos de 2017 e 2018 da empresa Norte Energia S.A., responsável pela construção e operação da Usina Hidrelétrica de Belo Monte. Estes relatórios, cujos dados foram quantificados e tabulados permitiram apreciar, e identificar as estratégias utilizadas pela Usina Hidrelétrica de Belo Monte, no gerenciamento de sua legitimidade social. Conforme os resultados, a categoria de legitimidade "pragmática", foi identificada em 40,32\% dos discursos analisados seguida, pelas categorias "cognitiva", com 34,27\% e, "moral”, com 25,40\% das evidenciações. A Norte Energia S.A fez uso, principalmente, de estratégias que visam ganhar legitimidade, a qual se destacou 68,95\% das evidenciações relacionadas a temas socioambientais. Em seguida, destacaram-se as finalidades "manter", com 29,44\% e "recuperar", com 1,61\% das evidenciações.

Palavras-chave: Teoria da Legitimidade. Divulgação Voluntária. Relatório Socioambiental.

\section{ABSTRACT}

This article analyzes the legitimacy strategies proposed by Suchman (1995) at the Belo Monte Hydroelectric Plant. The study is characterized as a case study, with a quantitative approach to the data and documentary analysis. To achieve the general objective, the annual and socio-environmental reports for the years 2017 and 2018 of the company Norte Energia S.A., responsible for the construction and operation of the Belo Monte Hydroelectric Plant, were used. These reports, whose data were quantified and tabulated, allowed to appreciate, and to identify the strategies used by the Belo Monte Hydroelectric Power Plant, in the management of its social legitimacy. according to the results, the "pragmatic" legitimacy category was identified in $40.32 \%$ of the speeches analyzed, followed by the "cognitive" categories, with $34.27 \%$ and, finally, "moral", with $25.40 \%$ of the evidences with socio-environmental themes, used by the company studied. Norte Energia S.A used mainly strategies aimed at gaining legitimacy, which stood out $68.95 \%$ of the disclosures related to socio-environmental issues. Then, the purposes "keep", with $29.44 \%$ and "recover", stood out with $1.61 \%$ of the disclosures.

Keywords: Theory of Legitimacy. Voluntary Disclosure. Social and Environmental Report.

\section{Celio Hissadi Inagaki}

Graduado em Ciências Contábeis pela Universidade Estadual do Oeste do Paraná (UNIOESTE), Campus de Foz do Iguaçu. Produtor Rural. E-mail: c_inagaki@hotmail. com

\section{Fabíola Graciele Besen \\ Bacharel em Ciências Contábeis. Mestre em Extensão Inovadora e Desenvolvimento Rural Sustentável. Doutorado em Desenvolvimento Rural Sustentável pela Universidade Estadual do Oeste do Paraná (Unioeste). Professora do Curso de Ciências Contábeis da Unioeste - Campus de Foz do Iguaçu. E-mail: fabiolagracielebesen@gmail.com}

\section{Juarez Bortolanza}

Pós - doutor em Gestão Universitária (UFSC - SC), Doutor em Engenharia da produção (UFSC - SC). Professor Adjunto do curso de Administração - UNIOESTE - MCR. E-mail: juarezbortolanza@gmail.com

\section{Ricardo Santana de Almeida} Bacharel em Ciências Contábeis. Mestrando em Contabilidade. Professor do Curso de Ciências Contábeis da Unioeste - Campus de Foz do Iguaçu. Foz do Iguaçu - PR. E-mail: Ricardo.santana.almeida@gmail.com 


\section{INTRODUÇÃO}

A abordagem sobre a responsabilidade social corporativa passou a ter mais relevância a partir da década de 1990, pois as estratégias competitivas e a eficiência das operações tornaram-se insuficientes para as organizações obterem sucesso e reconhecimento (Rocha e Goldschmidt, 2010). No Brasil, também ocorreu uma intensificação da discussão sobre o papel das empresas na minimização dos problemas sociais, da visão tradicional, na qual as empresas têm a função de gerar empregos e desenvolver produtos e serviços de forma lucrativa, por uma nova, que considera a necessidade de incorporar os interesses dos stakeholders (Rocha e Goldschmidt, 2010).

Neste cenário, Rocha e Goldschmidt (2010) destacam que a sociedade civil organizada passa a intensificar a cobrança sobre o impacto causado ao meio ambiente e a sociedade, chamando as empresas a prestar contas sobre suas atividades produtivas e socioambientais. Desta forma, ao buscar atender aos interesses relacionados a responsabilidade social, as organizações desenvolvem ações que visam suprir as demandas sociais e ambientais, além de impulsionar seu desempenho empresarial no mercado, pois a sociedade, passa a atribuir valor as organizações que integram os princípios da Responsabilidade Social Empresarial - RSE - em suas atividades (Feitosa, Souza e Gómez, 2014).

Esta crescente preocupação com os problemas de caráter ambiental e com o desenvolvimento sustentável das organizações tem estimulado o debate sobre as políticas de evidenciações contábeis (Dias Filho, 2007). Afinal, através da evidenciação de "[...] informações compulsórias e/ou voluntárias sobre seu relacionamento com o meio ambiente e social, as organizações buscam legitimar-se em seu ambiente, ou então manter sua legitimidade já reconhecida pela sociedade." (Beuren, Gubiani e Soares, 2013, p. 850).

A divulgação de informações de natureza social, para Ferreira, Pucci e Lopes (2004), deve ter como principal objetivo levar o maior número de informação possível sobre o comprometimento social da empresa que o publica, consistindo numa forma de prestação de contas da empresa para com a sociedade.

A divulgação de informações socioambientais, como prática voluntária visa a legitimação social, segundo Machado e Ott (2015), a qual é discutida pela Teoria da Legitimidade. Para Dias Filho, (2007, p. 06), essa teoria tem por base que "[...] existe uma espécie de "contrato social" entre as organizações e a sociedade em que atuam, representando um conjunto de expectativas implícitas ou explicitas de seus membros a respeito da forma como elas devem operar”. Assim, todo o esforço que as organizações fazem para que sejam vistas pela sociedade como socialmente responsáveis, é considerado uma estratégia, com o intuito de continuar extraindo do ambiente em que operam, os recursos necessários para cumprir seus objetivos com o menor custo possível (Dias Filho, 2007).

Frente ao crescente número de empresas que passaram a incorporar em seus relatórios contábeis, informações de conteúdo social e ambiental, diversos estudos buscaram explicar o motivo que levaram tais entidades a adotar esse procedimento voluntariamente (Dias Filho 2007). Tendo isso em vista, a Teoria da Legitimidade constitui uma alternativa para explicar e predizer as práticas de evidenciação voluntária, sendo utilizada, para examinar até que ponto essas políticas de evidenciações estão relacionadas à tentativa de construir, manter ou recuperar sua legitimidade (Dias Filho, 2007).

Uma tipologia aceita em estudos a respeito da Teoria da Legitimidade é a de Suchman (1995), o qual aponta três categorias de legitimação organizacional compreendendo pragmática, moral e cognitiva, nas quais classifica as estratégias de legitimação utilizadas por determinada organização. De acordo com Eugénio (2010, p. 116), em vários estudos que envolvem este tema, existe o consenso de que os relatos de natureza social e ambiental tem como principal motivo, "[...] o desejo, por parte da gestão, de legitimar vários aspectos das organizações, abrangendo também as operações do negócio.”

Uma atividade empresarial conhecida por causar grandes impactos sociais e ambientais são as hidrelétricas, devido às alterações associadas a formação de seu reservatório (Queiroz e Veiga, 2012), podendo gerar impactos como: a modificação dos rios barrados, a alteração da biota e dos ecossistemas, o deslocamento de cidades e povoações - inclusive indígenas e tradicionais -, a alteração do comportamento da bacia hidrográfica, além de causar assoreamentos com sua operação, que somado a outros fatores, podem acabar ocasionando mudanças na qualidade da água (Ministério do Meio Ambiente, 2019).

No Brasil, um desses empreendimentos hidrelétricos é a Usina de Belo Monte, que está instalada no rio Xingu, no estado do Pará. Atualmente, a empresa responsável por sua construção e operação é a Norte Energia S/A, uma sociedade anônima composta por empresas de diferentes segmentos de atuação (Norte Energia, 2017). Sua primeira unidade de geração de energia, entrou em operação em abril de 2016 e sua conclusão, se deu em novembro de 2019, após o início da operação comercial de sua $18^{a}$ unidade geradora (Norte Energia, 2021). Com sua conclusão, a Usina Hidrelétrica de Belo Monte se firmou como a maior hidrelétrica 100\% brasileira, possuindo uma capacidade instalada de $11.233,1 \mathrm{MW}$ e uma quantidade média de 4.571 MW de geração de energia (Norte Energia, 2021).

A partir de tais considerações, o objetivo do presente estudo é analisar a estratégia utilizada pela Usina Hidrelétrica de Belo Monte, para gerenciar sua legitimidade perante a sociedade, baseada nas estratégias de legitimidade propostas por Suchman (1995).

Estudiosos no assunto como Machado e Ott (2015), Farias, Andrade e Gomes (2017), Voltarelli e Zanchet (2017) e Voltarelli (2018), são alguns dos autores que buscaram identificar as estratégias de legitimação utilizadas pelas organizações, baseados nas estratégias de legitimidade propostas por Suchman (1995).

O estudo se torna relevante, pois através dele, pode-se analisar a utilização das demonstrações socioambientais pelas organizações no gerenciamento de sua legitimidade social. Dessa forma, a pesquisa busca contribuir no entendi- 
mento das estratégias de legitimidade utilizadas, além de tentar compreender a relação existente entre as organizações e a sociedade em que atuam. Além disso, torna-se interessante analisar os relatórios da Usina Hidrelétrica de Belo Monte, pois se trata de uma usina $100 \%$ brasileira instalada há poucos anos no país, sendo também, um empreendimento que tem um impacto relevante tanto no meio ambiente, quanto na sociedade em que está inserida.

O presente trabalho está estruturado em cinco seções, sendo esta introdução, a primeira, constando o problema de pesquisa, o objetivo, os objetivos específicos e a justificativa do estudo. Na segunda seção, são apresentados os conceitos relacionados a Teoria da Legitimidade e as estratégias de legitimação, além de abordar sobre demais estudos que tratam a respeito da aplicação desta teoria em outras organizações; na terceira seção descreve-se a metodologia utilizada; na quarta, foram analisados e tratados os resultados do estudo; e por fim, na última seção, encontram-se as considerações finais, além das referências bibliográficas.

\section{TEORIA DA LEGITIMIDADE}

A Teoria da Legitimidade tem suas raízes na Teoria Institucional (Machado e Ott, 2015) e na Teoria dos Contratos (Dias Filho, 2012). De acordo com Dias Filho (2012, p. 75), a Teoria dos Contratos é aquela que se baseia na ideia, de que "existe um contrato entre as organizações e a sociedade em que elas operam edificado em função do sistema de crenças e valores vigentes”. Assim, na perspectiva desta teoria, as organizações estariam sempre buscando adequar suas atividades, para estar de acordo com as expectativas da sociedade em que estão inseridas (Dias Filho, 2012).

À luz da teoria da legitimidade, os gestores têm o papel fundamental em perceber como a sociedade vê a organização. Caso as operações não estejam compatíveis com o contrato social, os gerentes terão que implantar estratégias corretivas, que precisarão ser divulgadas para serem efetivas na mudança de percepção da sociedade (Deegan, 2002, p. 296).

Segundo Dias Filho (2007, p. 06), a Teoria da Legitimidade tem por base a ideia de que "existe uma espécie de "contrato social" entre as organizações e a sociedade em que atuam, representando um conjunto de expectativas implícitas ou explícitas de seus membros a respeito da forma como elas devem operar".

Caso a sociedade perceba que a empresa não está atuando de forma legítima, poderia simplesmente revogar esse contrato, sendo esta revogação evidenciada, por exemplo, através da redução ou eliminação da demanda pelos produtos comercializados pela mesma, ou por ações do governo, com o aumento de impostos, multas ou leis para proibir atividades que estejam em desacordo com as expectativas da sociedade (Deegan, 2002).

Segundo Shocker e Sethi (1973), qualquer instituição social desempenha suas atividades por meio de um contrato social, segundo o qual sua sobrevivência e crescimento dependem, tendo suas bases, na entrega de alguns fins socialmente desejáveis para a sociedade em geral, assim como na distribuição de benefícios sociais ou políticos a grupos dos quais deriva seu poder. Neste sentido, não agir de acordo com o contrato social poderia ser considerado prejudicial para as operações em andamento de uma organização (Deegan, Rankin e Tobin, 2002). Desta forma, é de se esperar que as organizações se esforcem para que suas atividades sejam aceitas e percebidas como legítimas, buscando estabelecer uma conformidade entre suas atividades e as expectativas da sociedade em que atuam, legitimando-se "na medida em que conseguem alinhar suas práticas com as normas e padrões de comportamento defendidos no ambiente em que operam.” (Dias Filho, 2012, p.75).

Deegan (2002) ressalta que o gerenciamento da legitimidade nas organizações depende muito de sua comunicação com seus diversos públicos, estendendo-se significativamente além do discurso tradicional. Por isso, seu gerenciamento pode requerer diversas técnicas, além de uma consciência de que situações realmente precisam de respostas. Desta forma, segundo a Teoria da Legitimidade, as divulgações podem ser feitas para mostrar que a organização está de acordo com as expectativas da comunidade, ou também, com o intuito de alterar as expectativas da mesma (Deegan et al., 2002).

De acordo com O’Donovan (2002, p. 349), para que uma entidade gerencie sua legitimidade organizacional de maneira eficaz, deve seguir os seguintes passos contemplados do Quadro 1:

Quadro 1 - Passos para o gerenciamento da legitimidade organizacional

\begin{tabular}{|c|c|}
\hline Item & Descrição \\
a) & Identificar seus públicos de conferência. \\
b) & $\begin{array}{r}\text { Estabelecer quais são os valores sociais e ambientais de seus públicos e suas percepções sobre a corporação } \\
\text { (variáveis de pressão pública). }\end{array}$ \\
c) & $\begin{array}{r}\text { Decidir sobre o propósito ou objetivo de qualquer potencial resposta organizacional a ameaças de legitimidade. } \\
\text { d) }\end{array}$ \\
$\begin{array}{c}\text { Decidir quais táticas e opções de divulgação estão disponíveis e adequadas para o gerenciamento da legitimidade, } \\
\text { relacionadas ao propósito da resposta organizacional. }\end{array}$
\end{tabular}

Fonte: Adaptado de O’Donovan (2002, p. 349, tradução dos autores).

Segundo Eugénio (2010), um dos principais meios de divulgação de informações ambientais utilizados pelas organizações tem sido o relatório anual, sendo esta demonstração, utilizada pelos pesquisadores, como uma fonte para se 
analisar as motivações dos gestores ao prestar tais informações. Desta forma, a teoria da legitimidade tem sido utilizada para "[...] verificar até que ponto políticas de evidenciação contábil estão associadas à tentativa de construir, manter ou recuperar legitimidade organizacional.” (Dias Filho, 2007, p. 08).

Devido a crescente quantidade de organizações que passaram a incorporar em suas evidenciações contábeis, informações socioambientais, diversos estudos buscaram pesquisar os motivos pelos quais tais empresas adotaram esse procedimento de forma voluntária (Dias Filho, 2007). Nesse contexto, a Teoria da Legitimidade é a base teórica mais frequentemente utilizada na tentativa de explicar as políticas de divulgação social e ambiental corporativas (Deegan et al., 2002).

\subsection{Estratégias de Legitimidade propostas por Suchman (1995)}

Para Suchman (1995, p. 574, tradução dos autores), a legitimidade pode ser definida como “[...] uma percepção ou premissa generalizada de que as ações de uma organização são desejáveis, adequadas ou apropriadas em algum sistema socialmente construído de normas, valores, crenças e definições”. Segundo o autor, as organizações procuram legitimar-se por diversas razões e sua importância, dificuldade e esforços para se legitimar, podem variar de acordo com os objetivos traçados.

Ressalta-se ainda, que existem duas dimensões para tratar a respeito da legitimidade, sendo elas: a) a distinção entre continuidade e busca de credibilidade e b) distinção entre buscar apoio passivo e buscar apoio ativo. Na primeira dimensão, a legitimidade aumenta tanto a estabilidade quanto a compreensibilidade das atividades organizacionais, levando a persistência e afetando o modo como as pessoas enxergam a empresa. Na segunda, se uma organização desejar apenas que um determinado público a deixe em paz, a função da legitimidade pode ser baixa, mas se quiser uma audiência prolongada, as exigências em relação a legitimidade poderão ser mais rigorosas (Suchman, 1995).

As três categorias de estratégias de legitimidade são: pragmática, moral e cognitiva. Estas três categorias, apresentadas no Quadro 2, envolvem “[...] uma generalização percepção ou suposição de que atividades organizacionais são desejáveis, adequadas, ou apropriadas dentro de algum sistema socialmente construído [...]” (Suchman, 1995, p. 577).

Quadro 2 - Categorias de Estratégias de Legitimidade

\begin{tabular}{|c|c|c|c|c|c|c|c|}
\hline Categoria de Legitimidade & Descrição \\
Pragmática & $\begin{array}{c}\text { Essa é uma categoria de legitimidade, que está relacionada ao imediatismo da organização em } \\
\text { relação as respostas sobre a percepção de seu público-alvo. Ela pode se resumir a uma espécie de } \\
\text { legitimidade de troca, onde o público concede legitimidade às organizações que estão de acordo } \\
\text { com seus interesses, que compartilham dos mesmos valores, ou que são honestas e confiáveis. } \\
\text { Moral }\end{array}$ & $\begin{array}{c}\text { É uma categoria de legitimidade que se repousa em julgamentos, sobre se a atividade feita } \\
\text { pela empresa é a coisa certa a se fazer, geralmente, levando-se em consideração, se a atividade } \\
\text { efetivamente promove o bem-estar social. }\end{array}$ \\
Cognitiva & $\begin{array}{c}\text { Essa categoria pode envolver tanto apoio afirmativo ou uma simples aceitação de uma } \\
\text { organização por ela ser necessária ou inevitável. Ela decorre principalmente da disponibilidade de } \\
\text { modelos culturais, que proporcionam explicações aceitáveis para a organização e seus esforços. }\end{array}$ \\
\hline
\end{tabular}

Fonte: Suchman (1995).

Em seu estudo, Suchman (1995) criou categorias de legitimidade, que podem ser utilizados para analisar as evidenciações de diversas organizações. Segundo Farias et al. (2017), essas categorias não integram uma hierarquia, mas possuem duas importantes distinções entre si. "Primeiro, a legitimidade pragmática depende do interesse próprio da audiência, enquanto a legitimidade moral e a cognitiva envolvem regras culturais mais abrangentes” (Farias, et al., 2017, p. 860).

\subsection{Estudos Relacionados}

Trabalhos como os de Machado e Ott (2015), Farias, Andrade e Gomes (2017), Voltarelli e Zanchet (2017) e Voltarelli (2018), são alguns exemplos de estudos brasileiros, que buscaram identificar as estratégias de legitimação utilizadas pelas organizações, através da tipologia de Suchman (1995).

No estudo de Machado e Ott (2015), foi analisado como as empresas brasileiras de capital aberto utilizavam a evidenciação ambiental para se legitimar. Nele, os autores examinaram as informações ambientais divulgadas em 2013, pelas empresas que faziam parte da carteira do Índice de Sustentabilidade Empresarial - ISE - da BM\&FBOVESPA, utilizando para isso, a tipologia de estratégias de legitimação propostas por Suchman. Com isso, os autores concluíram que as empresas pesquisadas evidenciavam suas informações ambientais principalmente com o intuito de ganhar legitimidade, utilizando de forma equilibrada, as categorias pragmática, moral e cognitiva em suas evidenciações (Machado e Ott, 2015). 
Farias, Andrade e Gomes (2017), utilizaram a tipologia de Suchman para identificar as estratégias de legitimidade mais utilizadas pelas empresas brasileiras destinatárias do pedido do Carbon Disclosure Project - CDP, no período de 2006 a 2010. Os dados primários foram coletados por meio de questionário e os secundários, através dos sites institucionais, relatórios do CDP e através do registro público de emissões da Fundação Getúlio Vargas - FGV. Após análise dos dados, os autores constataram que a legitimidade pragmática e o critério ganho, foram os mais evidenciados pelas empresas, concluindo que o CDP vem sendo utilizado pelas empresas estudadas como um meio de obter aceitação e legitimidade perante as partes interessadas (Farias et al., 2017).

Voltarelli e Zanchet (2017), através da teoria da legitimidade, buscaram analisar como a empresa Itaipu Binacional gerenciava sua legitimidade social por meio da divulgação de informações socioambientais. Para isso, coletaram os relatórios de sustentabilidade disponíveis no site da empresa, referente aos anos de 2011 a 2015. Após a análise dos dados, os resultados obtidos com a pesquisa indicaram que na divulgação dos relatórios de sustentabilidade, a Itaipu Binacional buscou dar maior ênfase na forma cognitiva, seguida pela pragmática e depois moral (Voltareli e Zanchet, 2017). Os autores concluíram que de maneira geral, a empresa buscou principalmente: “[...] popularizar e padronizar seus modelos, cooptar integrantes, vincular-se a instituições visando apoio para desenvolver diversas ações sociais e ambientais e demonstrar que produz resultados adequados para a sociedade.” (Voltareli e Zanchet, 2017, p. 04).

Voltarelli (2018), analisou em sua pesquisa, como a divulgação voluntária sobre o meio ambiente natural pode contribuir para a legitimidade organizacional das usinas hidrelétricas. Para alcançar seu objetivo, a autora analisou os relatórios de sustentabilidade divulgados por empresas que operam usinas hidrelétricas no estado do Paraná, e realizou entrevistas com os gestores que tiveram participação na elaboração dos relatórios de sustentabilidade destas mesmas empresas (Voltarelli, 2018). Concluiu que as divulgações voluntárias a respeito do meio ambiente natural, contribuem principalmente no contexto de ganhar legitimidade organizacional, por meio da utilização de estratégias de legitimidade das categorias pragmática, moral e cognitiva (Voltarelli, 2018).

Ao analisar os trabalhos relacionados com o presente estudo, é possível observar que seus autores, de modo geral, identificaram nos relatórios divulgados por suas empresas estudadas, que elas buscavam publicar informações com o intuito de ganhar legitimidade organizacional, demonstrando em suas evidenciações, que estão buscando se adequar as exigências da sociedade.

\section{METODOLOGIA}

O presente estudo se caracteriza como estudo de caso, pois utiliza nesta pesquisa, apenas os relatórios de sustentabilidade relacionados à Usina Hidrelétrica de Belo Monte. De acordo com Gil (2002, p. 54), o estudo de caso, "consiste no estudo profundo e exaustivo de um ou mais objetos, de maneira que permita seu amplo e detalhado conhecimento [...]”.

Em relação a técnica, foi utilizado neste estudo a pesquisa documental, pois os dados coletados são provenientes dos relatórios de sustentabilidade da Norte Energia S/A, empresa responsável pela construção e operação da Usina Hidrelétrica de Belo Monte. Marconi e Lakatos (2003, p. 174) afirmam, que "a característica da pesquisa documental é que a fonte de coleta de dados está restrita a documentos, escritos ou não, constituindo o que se denomina de fontes primárias".

A pesquisa também se caracteriza como descritiva, pois segundo Gil (2002, p. 42), "as pesquisas descritivas têm como objetivo primordial a descrição das características de determinada população ou fenômeno ou, então, o estabelecimento de relações entre variáveis”. No entendimento de Raupp e Beuren (2006), nesse tipo de pesquisa, são empregadas desde as mais simples até as mais sofisticadas técnicas estatísticas.

O objeto do estudo é a Usina Hidrelétrica de Belo Monte, e envolveu os relatórios de sustentabilidade da Norte Energia S/A, empresa responsável pela administração desta Usina, referentes aos anos de 2017 e 2018, disponíveis no endereço eletrônico da entidade. Com isso, as informações foram analisadas de acordo com as categorias de análise propostas por Suchman (1995): ganhar, manter ou recuperar a legitimidade. Às subcategorias de análise, correspondentes à forma com que as empresas gerenciam sua legitimidade, podendo ser de maneira pragmática, moral ou cognitiva. E as estratégias de legitimidade, que foram organizadas em ações pertencentes a cada categoria e subcategoria.

Para a classificação dos relatórios que tratam das informações socioambientais da empresa estudada, foi feita a leitura de cada parágrafo dos relatórios que foram classificados conforme alguns parâmetros apresentados no Quadro 3.

Quadro 3 - Parâmetros adotados na classificação da evidenciação ambiental

\begin{tabular}{|c|c|c|}
\hline $\begin{array}{c}\text { Estratégia de } \\
\text { Legitimidade }\end{array}$ & $\begin{array}{r}\text { Categoria / } \\
\text { Subcategoria }\end{array}$ & $\begin{array}{c}\text { Ideia central da descrição do relatório } \\
\begin{array}{c}\text { Responder as } \\
\text { necessidades }\end{array}\end{array}$ \\
$\begin{array}{c}\text { Ganhar / } \\
\text { Pragmática }\end{array}$ & $\begin{array}{r}\text { Relata o cumprimento de exigências legais ou acordos realizados, assim como } \\
\text { realização de ações ambientais obedecendo às necessidades sociais. Relato de } \\
\text { investimentos em pesquisas. }\end{array}$ \\
$\begin{array}{c}\text { Ganhar / } \\
\text { Pragmática }\end{array}$ & $\begin{array}{r}\text { Associa-se a parceiros para o desenvolvimento de ações sustentáveis, como, por } \\
\text { exemplo, empresas de reciclagem, universidades, comunidade, etc. }\end{array}$
\end{tabular}




\begin{tabular}{|c|c|c|}
\hline $\begin{array}{l}\text { Estratégia de } \\
\text { Legitimidade }\end{array}$ & $\begin{array}{l}\text { Categoria / } \\
\text { Subcategoria }\end{array}$ & Ideia central da descrição do relatório \\
\hline Construir reputação & $\begin{array}{l}\text { Ganhar / } \\
\text { Pragmática }\end{array}$ & $\begin{array}{c}\text { Relata sua forte reputação em atividades correlatas, assim como a declaração de } \\
\text { valores investidos em projetos ambientais, ações de sensibilização social às questões } \\
\text { relacionadas à preservação do meio ambiente. }\end{array}$ \\
\hline $\begin{array}{l}\text { Localizar público } \\
\text { amigável }\end{array}$ & $\begin{array}{l}\text { Ganhar / } \\
\text { Pragmática }\end{array}$ & Identifica locais/regiões para receber ações ambientais. \\
\hline $\begin{array}{l}\text { Recrutar } \\
\text { cooperadores } \\
\text { amigáveis }\end{array}$ & $\begin{array}{l}\text { Ganhar / } \\
\text { Pragmática }\end{array}$ & Seleciona parceiros para desenvolver ações sustentáveis. \\
\hline Anunciar produto & $\begin{array}{l}\text { Ganhar / } \\
\text { Pragmática }\end{array}$ & Relata que o produto é sustentável. \\
\hline Anunciar imagem & $\begin{array}{l}\text { Ganhar / } \\
\text { Pragmática }\end{array}$ & Relata que a empresa é sustentável, preocupada com questões ambientais. \\
\hline $\begin{array}{l}\text { Produzir resultados } \\
\text { adequados }\end{array}$ & Ganhar / Moral & $\begin{array}{l}\text { Relata os resultados de ações que buscam a redução dos impactos ambientais, } \\
\text { contribuindo para a preservação do meio ambiente. Ex. redução no consumo de água. }\end{array}$ \\
\hline $\begin{array}{l}\text { Incorporar-se a } \\
\text { instituições }\end{array}$ & Ganhar / Moral & $\begin{array}{c}\text { Relata a participação em grupos de pesquisa, fundações, conselhos junto a outras } \\
\text { instituições. }\end{array}$ \\
\hline $\begin{array}{l}\text { Oferecer } \\
\text { demonstrações } \\
\text { simbólicas }\end{array}$ & Ganhar / Moral & $\begin{array}{c}\text { Relata "buscar" aprimorar processos, melhorar a eficiência sustentável e realizar } \\
\text { diversas ações ambientais, porém sem especificá-las. }\end{array}$ \\
\hline Definir metas & Ganhar / Moral & Relato de metas sustentáveis. \\
\hline $\begin{array}{l}\text { Demonstrar } \\
\text { sucesso }\end{array}$ & Ganhar / Moral & $\begin{array}{c}\text { Relata o sucesso no alcance de resultados das ações ambientais, como por exemplo, o } \\
\text { plantio de grande quantidade de mudas de plantas. }\end{array}$ \\
\hline Fazer adeptos & Ganhar / Moral & Destaca as vantagens de ações ambientais, programas/projetos. \\
\hline Reproduzir normas & Ganhar / Cognitiva & $\begin{array}{l}\text { Relata que observa os padrões legais e normativos do setor no desenvolvimento de } \\
\text { suas operações. }\end{array}$ \\
\hline $\begin{array}{l}\text { Formalizar } \\
\text { operações }\end{array}$ & Ganhar / Cognitiva & Relata a adoção de modelos/projetos/ações sustentáveis já legitimados. \\
\hline $\begin{array}{l}\text { Profissionalizar } \\
\text { operações }\end{array}$ & Ganhar / Cognitiva & $\begin{array}{l}\text { Relato de treinamentos, cursos, seminários para capacitação de seus agentes em } \\
\text { busca da realização de ações sustentáveis ou para adotar sistemas já legitimados. }\end{array}$ \\
\hline Buscar certificação & Ganhar / Cognitiva & Relata certificações obtidas ou intenção de ações para essa finalidade. \\
\hline Persistir & Ganhar / Cognitiva & $\begin{array}{c}\begin{array}{c}\text { Relata melhorias em processos adotados, evidenciando com isso, a permanências } \\
\text { desses processos. }\end{array}\end{array}$ \\
\hline $\begin{array}{l}\text { Popularizar novos } \\
\text { modelos }\end{array}$ & Ganhar / Cognitiva & Populariza os modelos/programas/projetos sustentáveis adotados. \\
\hline $\begin{array}{l}\text { Padronizar novos } \\
\text { modelos }\end{array}$ & Ganhar / Cognitiva & $\begin{array}{l}\text { Relata o estabelecimento de normas/regulamentos que visem à padronização de } \\
\text { ações ambientais. }\end{array}$ \\
\hline $\begin{array}{l}\text { Consultar opinião } \\
\text { de líderes }\end{array}$ & $\begin{array}{l}\text { Manter / } \\
\text { Pragmática }\end{array}$ & $\begin{array}{c}\text { Relata da participação do público externo e interno na definição de metas/ações } \\
\text { sustentáveis. }\end{array}$ \\
\hline
\end{tabular}




\begin{tabular}{|c|c|c|}
\hline $\begin{array}{l}\text { Estratégia de } \\
\text { Legitimidade }\end{array}$ & $\begin{array}{l}\text { Categoria / } \\
\text { Subcategoria }\end{array}$ & Ideia central da descrição do relatório \\
\hline $\begin{array}{l}\text { Monitorar a } \\
\text { confiabilidade }\end{array}$ & $\begin{array}{l}\text { Manter / } \\
\text { Pragmática }\end{array}$ & $\begin{array}{c}\text { Relata o monitoramento de operações para evitar impactos ambientais, mantendo a } \\
\text { confiabilidade nas operações. }\end{array}$ \\
\hline $\begin{array}{l}\text { Comunicar-se } \\
\text { honestamente }\end{array}$ & $\begin{array}{l}\text { Manter / } \\
\text { Pragmática }\end{array}$ & $\begin{array}{c}\text { Relata situações negativas, como por exemplo, metas não alcançadas e impactos } \\
\text { ambientais ocorridos. }\end{array}$ \\
\hline Estocar confiança & $\begin{array}{l}\text { Manter / } \\
\text { Pragmática }\end{array}$ & $\begin{array}{c}\text { Relata a participação da empresa frente à elaboração de normas e padrões ambientais } \\
\text { a serem seguidos pelo setor. }\end{array}$ \\
\hline $\begin{array}{c}\text { Consultar } \\
\text { categorias } \\
\text { profissionais }\end{array}$ & Manter / Moral & Relata consultas realizadas junto a órgãos ligados ao meio ambiente. \\
\hline $\begin{array}{l}\text { Monitorar a } \\
\text { responsabilidade }\end{array}$ & Manter / Moral & $\begin{array}{l}\text { Reconhece algum tipo de impacto ambiental ocorrido e indica as ações desenvolvidas } \\
\text { para minimizar este impacto. }\end{array}$ \\
\hline $\begin{array}{l}\text { Comunicar-se } \\
\text { oficialmente }\end{array}$ & Manter / Moral & $\begin{array}{l}\text { Relata a comunicação de seus impactos ambientais em eventos, jornais, dentre outros } \\
\text { meios de comunicação em massa. }\end{array}$ \\
\hline $\begin{array}{l}\text { Estocar opiniões } \\
\text { favoráveis }\end{array}$ & Manter / Moral & Relata alguma opinião favorável de autoridade ou instituição legitimada. \\
\hline $\begin{array}{l}\text { Consultar aqueles } \\
\text { que têm dúvidas }\end{array}$ & Manter / Cognitiva & $\begin{array}{c}\text { Relata a realização de visitas abertas à sociedade em suas unidades onde possam ser } \\
\text { sanadas possíveis dúvidas. }\end{array}$ \\
\hline Visar clareza & Manter / Cognitiva & Explica o funcionamento de programas/processos ambientais. \\
\hline Falar pontualmente & Manter / Cognitiva & Falar do assunto com naturalidade. \\
\hline Estocar conexões & Manter / Cognitiva & Faz conexão entre políticas ambientais e resultados financeiros. \\
\hline Rejeitar & $\begin{array}{l}\text { Recuperar / } \\
\text { Pragmática }\end{array}$ & Negar a participação ou responsabilidade na ocorrência de algum evento negativo. \\
\hline Criar monitores & $\begin{array}{l}\text { Recuperar / } \\
\text { Pragmática }\end{array}$ & Relata a criação de comissão/setores para apurar algum evento negativo. \\
\hline $\begin{array}{l}\text { Desculpar / } \\
\text { justificar }\end{array}$ & Recuperar / Moral & A empresa lamenta algum fato negativo e justifica o acontecido. \\
\hline Substituir pessoal & Recuperar / Moral & Relata a substituição de pessoal responsável por algum evento negativo. \\
\hline Rever práticas & Recuperar / Moral & $\begin{array}{l}\text { Relata a renúncia de utilizar determinados processos devido aos impactos negativos } \\
\text { ao meio ambiente. }\end{array}$ \\
\hline Reconfigurar & Recuperar / Moral & $\begin{array}{c}\text { Relata a readequação em processos para melhorá-los, ou para minimizar impactos } \\
\text { ambientais. }\end{array}$ \\
\hline Explicar & $\begin{array}{l}\text { Recuperar / } \\
\text { Cognitiva }\end{array}$ & Explica os motivos que levaram ao acontecimento de algum evento negativo. \\
\hline
\end{tabular}

Fonte: Adaptado de Machado e Ott (2015, p. 144).

Após a análise do conteúdo dos relatórios de sustentabilidade, os dados coletados foram quantificados através da contagem dos parágrafos que foram classificados em cada estratégia de legitimidade. Em seguida, as quantidades obtidas de cada estratégia, foram separadas e tabuladas conforme as categorias e subcategorias apresentadas no quadro acima.

Assim, foi possível identificar quais estratégias a Usina Hidrelétrica de Belo Monte utiliza em seus relatórios, para gerenciar sua legitimidade social. A quantidade de ocorrências de cada tipo de estratégia foi transcrita no software Mi- 
crosoft Excel 2019, totalizando 248 parágrafos que tratavam de assuntos relacionados a informações socioambientais divulgadas pela companhia.

\section{DESENVOLVIMENTO}

Esta seção, contempla uma breve apresentação da Usina Hidrelétrica de Belo Monte, assim como da empresa responsável por sua construção e operação, a Norte Energia S.A. Na sequência estão as análises dos dados obtidos através do estudo dos relatórios divulgados pela companhia estudada, referentes aos anos de 2017 e 2018.

\subsection{Apresentação da Empresa}

Instalada no rio Xingu, no estado do Pará, a UHE Belo Monte é considerada a maior usina hidrelétrica $100 \%$ brasileira, possuindo uma capacidade instalada de 11.233,1 MW e uma quantidade média de geração de energia de $4.571 \mathrm{MW}$ (Norte Energia, n.d.). Atualmente, a empresa responsável por sua construção e operação é a Norte Energia S.A., uma sociedade de propósito específico, que venceu o leilão de concessão em abril de 2010 (Norte Energia, 2018).

Para a formação de seu reservatório, a UHE Belo Monte inundou uma área total de $478 \mathrm{Km}^{2}$ no estado do Pará, sendo: $239,2 \mathrm{Km}^{2}$ no município de Vitória do Xingu, $238 \mathrm{Km}^{2}$ em Altamira e 0,8 Km² em Brasil Novo (Norte Energia, 2018). A Norte Energia relata que "o potencial hídrico do rio Xingu só pôde ser aproveitado para geração de energia elétrica, após a definição de diversas ações socioambientais que condicionaram legalmente, a construção e o início de operação da UHE Belo Monte, no Pará” (Norte Energia, 2018, p. 20). E, que a companhia tem produzido periodicamente relatórios de sustentabilidade que são submetidos à avaliação do Instituto Brasileiro do Meio Ambiente e dos Recursos Naturais Renováveis - IBAMA -, com o objetivo de informar sobre o andamento das ações solicitadas nas condicionantes de seu licenciamento (Norte Energia, 2018).

De acordo com a empresa, a prestação de contas de suas atividades e desempenho são revisados por auditoria externa independente e seguem as normas internacionais de contabilidade definidas pela International Financial Reporting Initiative - IFRS (Norte Energia, n.d.). E em relação a elaboração de seus relatórios de sustentabilidade, a Norte Energia destaca, que ela segue os padrões da GRI, bem como as orientações presentes no Manual da ANEEL (Norte Energia, 2018).

\subsection{Análise dos Resultados}

Os relatórios de sustentabilidade divulgados pela Norte Energia S.A. analisados neste estudo, abrangeram os anos de 2017 e 2018. Através da análise destes relatórios, foi possível identificar as estratégias de legitimidade mais utilizadas pela empresa, possibilitando assim, o estabelecimento de análises e discussões acerca das informações evidenciadas, cujos resultados fazem parte do próximo tópico.

\subsubsection{Legitimidade Pragmática}

Na Tabela 1, são apresentadas as frequências evidenciadas nos relatórios de sustentabilidade da Norte Energia S.A., referentes aos anos de 2017 e 2018, em atendimento na estratégia de legitimidade pragmática propostas por Suchman (1995).

Tabela 1 - Estratégias de legitimação pragmática

\begin{tabular}{|c|c|c|c|c|c|c|}
\hline \multirow{2}{*}{\multicolumn{3}{|c|}{ Estratégias para legitimação Pragmática }} & \multicolumn{2}{|c|}{ Ano } & \multirow{2}{*}{$\begin{array}{c}\text { Total } \\
\text { Geral }\end{array}$} & \multirow{2}{*}{$\begin{array}{c}\begin{array}{c}\% \text { da } \\
\text { Categoria }\end{array} \\
34,00 \%\end{array}$} \\
\hline & & & 2017 & 2018 & & \\
\hline Ganhar & Selecionar mercados & $\begin{array}{c}\text { Responder às necessidades } \\
\text { Cooptar integrantes } \\
\text { Construir reputação } \\
\text { Localizar públicos amistosos } \\
\text { Recrutar cooperadores amistosos } \\
\text { Anunciar produto } \\
\text { Anunciar a imagem }\end{array}$ & $\begin{array}{l}17 \\
3 \\
10 \\
5 \\
2 \\
1 \\
6\end{array}$ & $\begin{array}{l}17 \\
4 \\
7 \\
6 \\
0 \\
1 \\
5\end{array}$ & $\begin{array}{c}34 \\
7 \\
17 \\
11 \\
2 \\
2 \\
11\end{array}$ & $\begin{array}{r}34,00 \% \\
7,00 \% \\
17,00 \% \\
11,00 \% \\
2,00 \% \\
2,00 \% \\
11,00 \%\end{array}$ \\
\hline \multicolumn{3}{|c|}{ Total Ano - Ganhar } & 44 & 40 & 84 & $84,00 \%$ \\
\hline
\end{tabular}




\begin{tabular}{|c|c|c|c|c|c|c|}
\hline \multirow{2}{*}{\multicolumn{3}{|c|}{ Estratégias para legitimação Pragmática }} & \multicolumn{2}{|c|}{ Ano } & \multirow{3}{*}{$\begin{array}{c}\text { Total } \\
\text { Geral }\end{array}$} & \multirow{3}{*}{$\begin{array}{c}\begin{array}{c}\% \text { da } \\
\text { Categoria }\end{array} \\
3,00 \%\end{array}$} \\
\hline & & & 2017 & 2018 & & \\
\hline \multirow{4}{*}{ Manter } & Monitorar interesses & Consultar a opinião de líderes & 1 & 2 & & \\
\hline & \multirow{3}{*}{ Favorecer trocas } & Monitorar a confiabilidade & 3 & 3 & 6 & $6,00 \%$ \\
\hline & & Comunicar-se honestamente & 2 & 0 & 2 & $2,00 \%$ \\
\hline & & Estocar confiança & 3 & 2 & 5 & $5,00 \%$ \\
\hline \multicolumn{3}{|c|}{ Total Ano - Manter } & 9 & 7 & 16 & $16,00 \%$ \\
\hline \multirow{2}{*}{ Reparar } & Rejeitar & Rejeitar & 0 & 0 & 0 & $0,00 \%$ \\
\hline & Criar monitores & Criar monitores & 0 & 0 & 0 & $0,00 \%$ \\
\hline \multicolumn{3}{|c|}{ Total Ano - Reparar } & $\mathbf{0}$ & 0 & 0 & $0,00 \%$ \\
\hline \multicolumn{3}{|c|}{ Total Categoria Pragmática } & 53 & 47 & 100 & $100,00 \%$ \\
\hline \multicolumn{5}{|c|}{ Total Geral de Parágrafos } & \multicolumn{2}{|r|}{248} \\
\hline
\end{tabular}

Fonte: Elaborado pelos autores, conforme dados da pesquisa (2020).

Conforme é possível observar na Tabela 1, a predominância da finalidade "ganhar", corresponde a 84\% desta categoria de legitimidade, demonstrando assim, elevar a percepção que a sociedade tem da Norte Energia S.A. No que tange a finalidade "manter" com 16\% das evidenciações, e por fim a finalidade "reparar", sem nenhuma divulgação nos relatórios de sustentabilidade da empresa.

Cabe destacar como pode ser observado na Tabela 1, que houve maiores evidenciações das ações estratégicas: "responder as necessidades", “construir reputação", "localizar públicos amistosos” e "anunciar a imagem”. Como forma de demonstrar que está respondendo as necessidades, a empresa buscou relatar o cumprimento de exigências legais ou acordos realizados, além da prática de ações ambientais que respondam as necessidades sociais, conforme pode ser observado:

"Em atendimento à legislação de compensação ambiental, a Norte Energia está investindo R \$ 135 milhões para a viabilização de Unidades de Conservação (UCs) novas e apoio a UCs existentes na região amazônica, disponibilizando tais recursos ao Instituto Chico Mendes de Conservação da Biodiversidade (ICMBio) e ao Instituto de Desenvolvimento Florestal e da Biodiversidade do Estado do Pará (Ideflor-bio), vinculado à Secretaria de Estado e Meio Ambiente e Sustentabilidade do Pará (SEMAS). Tais recursos são aplicados principalmente em regularização fundiária, elaboração de planos de manejo e investimentos na infraestrutura dessas UCs” (Norte Energia, 2018, p. 50).

Já com o intuito de construir sua reputação, a empresa buscou evidenciar os valores investidos em projetos ambientais, ações de sensibilização social e questões relacionadas à preservação do meio ambiente, como pode ser comprovada na afirmativa: "Sobre os investimentos realizados em 2017, a Norte Energia empregou R 393 milhões em atividades socioambientais desenvolvidas na região do médio Xingu, como atendimento ao Projeto Básico Ambiental (PBA) e também ao Componente Indígena, o PBA-CI" (Norte Energia, 2017, p. 8).

Com o objetivo de localizar públicos amistosos, a Norte Energia S.A. apresentou em seus relatórios de sustentabilidade, locais para receber suas ações ambientais, com o seguinte relato:

"Composto por 117 projetos, o PBA atende os municípios da Área de Influência Direta (AID) e da Área de Influência Indireta (AII) do Empreendimento. Esses projetos envolvem ações nas áreas de saúde, educação, habitação, saneamento básico, segurança e assistência social" (Norte Energia, 2018, p. 35).

E por fim, visando anunciar a sua imagem, a companhia buscou evidenciar em seus relatórios de sustentabilidade, que ela é sustentável e preocupada com questões ambientais, ao relatar compromissos como por exemplo: "A cada ação socioambiental realizada, a Norte Energia reitera o compromisso de respeito ao território e à cultura das comunidades locais e dos povos indígenas" (Norte Energia, 2017, p. 23). A continuidade de afirmativas de legitimidade da empresa faz parte do próximo tópico.

\subsubsection{Legitimidade Moral}

Na Tabela 2, são apresentadas as frequências evidenciadas nos relatórios de sustentabilidade da Norte Energia S.A., referentes aos anos de 2017 e 2018, conforme os itens de estratégia de legitimidade moral propostos por Suchman (1995). 
Tabela 2 - Estratégias de legitimação moral

\begin{tabular}{|c|c|c|c|c|c|c|}
\hline \multirow{2}{*}{\multicolumn{3}{|c|}{ Estratégias para legitimação Moral }} & \multicolumn{2}{|c|}{ Ano } & \multirow{2}{*}{$\begin{array}{c}\text { Total } \\
\text { Geral }\end{array}$} & \multirow{2}{*}{$\begin{array}{c}\begin{array}{c}\% \text { da } \\
\text { Categoria }\end{array} \\
23,81 \%\end{array}$} \\
\hline & & & 2017 & 2018 & & \\
\hline Ganhar & $\begin{array}{c}\text { Selecionar o domínio } \\
\text { Persuadir }\end{array}$ & $\begin{array}{c}\text { Produzir resultados adequados } \\
\text { Incorporar-se a instituições } \\
\text { Oferecer demonstrações simbólicas } \\
\text { Definir metas } \\
\text { Demonstrar sucesso } \\
\text { Fazer proselitismo }\end{array}$ & $\begin{array}{l}7 \\
0 \\
0 \\
0 \\
14 \\
2\end{array}$ & $\begin{array}{l}8 \\
0 \\
0 \\
0 \\
17 \\
2\end{array}$ & $\begin{array}{r}15 \\
0 \\
0 \\
0 \\
31 \\
4\end{array}$ & $\begin{array}{l}23,81 \% \\
0,00 \% \\
0,00 \% \\
0,00 \% \\
49,21 \% \\
6,35 \%\end{array}$ \\
\hline \multicolumn{3}{|c|}{ Total Ano - Ganhar } & 23 & 27 & 50 & $79,37 \%$ \\
\hline Manter & $\begin{array}{l}\text { Monitorar ética } \\
\begin{array}{c}\text { Favorecer a boa } \\
\text { conduta }\end{array}\end{array}$ & $\begin{array}{l}\text { Consultar categorias profissionais } \\
\text { Monitorar a responsabilidade } \\
\text { Comunicar-se oficialmente } \\
\text { Estocar opiniões favoráveis }\end{array}$ & $\begin{array}{l}0 \\
3 \\
3 \\
0\end{array}$ & $\begin{array}{l}0 \\
3 \\
2 \\
0\end{array}$ & $\begin{array}{l}0 \\
6 \\
5 \\
0\end{array}$ & $\begin{array}{l}0,00 \% \\
9,52 \% \\
7,94 \% \\
0,00 \%\end{array}$ \\
\hline \multicolumn{3}{|c|}{ Total Ano - Manter } & 6 & 5 & 11 & $17,46 \%$ \\
\hline Reparar & Desculpar / Justificar & $\begin{array}{c}\text { Desculpar / Justificar } \\
\text { Substituir pessoal } \\
\text { Rever as práticas } \\
\text { Reconfigurar }\end{array}$ & $\begin{array}{l}1 \\
0 \\
0 \\
0\end{array}$ & $\begin{array}{l}1 \\
0 \\
0 \\
0\end{array}$ & $\begin{array}{l}2 \\
0 \\
0 \\
0\end{array}$ & $\begin{array}{l}3,17 \% \\
0,00 \% \\
0,00 \% \\
0,00 \%\end{array}$ \\
\hline \multicolumn{3}{|c|}{ Total Ano - Reparar } & 1 & 1 & 2 & $3,17 \%$ \\
\hline \multicolumn{3}{|c|}{ Total Categoria Moral } & 30 & 33 & 63 & $100,00 \%$ \\
\hline \multicolumn{5}{|c|}{ Total Geral Parágrafos } & \multicolumn{2}{|c|}{248} \\
\hline
\end{tabular}

Fonte: Elaborado pelos autores, conforme dados da pesquisa (2020).

Quanto a legitimidade moral, consta na Tabela 2, que houve a predominância da finalidade "ganhar", que correspondeu a 79,37\% dos discursos apresentados pela empresa, seguida das finalidades "manter", com 17,46\% e "reparar", com $3,17 \%$ das evidenciações. Isso indica, que a companhia busca direcionar suas atividades com o intuito de estar de acordo com os ideais de seu público, buscando assim, uma visão ética da sociedade em relação a ela.

$\mathrm{Na}$ Tabela 2, também é possível identificar as estratégias de legitimidade moral mais utilizadas pela Norte Energia S.A., que foram as de: "demonstrar sucesso", "produzir resultados adequados" e "monitorar a responsabilidade". Para demonstrar sucesso para seu público, a companhia buscou relatar por exemplo, o alcance dos resultados de suas ações socioambientais, conforme pode ser observado:

\begin{abstract}
"Na área de saúde pública, a Norte Energia investe, desde 2011, no Plano de Ação para Controle da Malária (PACM). A continuidade das ações do PACMc nos cinco municípios da AID da UHE Belo Monte tem sido de extrema importância para redução e controle da malária na região. Quando são comparados os dados de 2018 em relação a 2011, registra-se uma redução de 97,5\% e 94,5\%, quando são incluídos os dados do município de Pacajá” (Norte Energia, 2018, p.36).
\end{abstract}

A Norte Energia S.A. também buscou demonstrar que produz resultados adequados, ao relatar o resultado de suas ações que visam a redução de seus impactos ambientais, como pode ser observado no trecho a seguir: "A Norte Energia realizou centenas de ações de resgate e salvamento da ictiofauna, totalizando mais de $218 \mathrm{mil} \mathrm{kg}$ de peixes resgatados e soltos no rio Xingu e seus tributários” (Norte Energia, 2018, p. 49).

Como forma de demonstrar que está monitorando a sua responsabilidade, a companhia buscou evidenciar em seus relatórios, que reconhece os impactos ambientais ocorridos, indicando também as ações desenvolvidas para minimizá-los, conforme ações estabelecidas: "Como medida compensatória para a formação dos reservatórios, ficou estabelecido que o entorno dos trechos inundados deve formar uma faixa de Área de Preservação Permanente (APP) com largura média de 500 metros" (Norte Energia, 2018, p. 50). 


\subsubsection{Legitimidade Cognitiva}

Na Tabela 3, são apresentadas as frequências evidenciadas nos relatórios de sustentabilidade da Norte Energia S.A., referentes aos anos de 2017 e 2018, conforme os itens de estratégia de legitimidade cognitiva propostos por Suchman (1995).

Tabela 3 - Estratégias de legitimação cognitiva

\begin{tabular}{|c|c|c|c|c|c|c|}
\hline \multirow{2}{*}{\multicolumn{3}{|c|}{ Estratégias para legitimação Cognitiva }} & \multicolumn{2}{|c|}{ Ano } & \multirow{2}{*}{$\begin{array}{l}\text { Total } \\
\text { Geral }\end{array}$} & \multirow{2}{*}{$\begin{array}{c}\% \text { da } \\
\text { Categoria }\end{array}$} \\
\hline & & & 2017 & 2018 & & \\
\hline \multirow{7}{*}{ Ganhar } & \multirow{3}{*}{ Adaptar-se aos modelos } & Reproduzir normas & 5 & 6 & 11 & $12,94 \%$ \\
\hline & & Formalizar as operações & 0 & 0 & 0 & $0,00 \%$ \\
\hline & & Profissionalizar as operações & 1 & 1 & 2 & $2,35 \%$ \\
\hline & \multirow[t]{2}{*}{ Selecionar rótulos } & Buscar certificação & 0 & 0 & 0 & $0,00 \%$ \\
\hline & & Persistir & 2 & 1 & 3 & $3,53 \%$ \\
\hline & \multirow[t]{2}{*}{ Institucionalizar } & Popularizar novos modelos & 7 & 8 & 15 & $17,65 \%$ \\
\hline & & Padronizar novos modelos & 3 & 3 & 6 & $7,06 \%$ \\
\hline \multicolumn{3}{|c|}{ Total Ano - Ganhar } & 18 & 19 & 37 & $43,53 \%$ \\
\hline \multirow{4}{*}{ Manter } & \multirow[t]{2}{*}{ Monitorar perspectivas } & Consultar aqueles que têm dúvidas & 0 & 0 & 0 & $0,00 \%$ \\
\hline & & Visar clareza & 12 & 15 & 27 & $31,76 \%$ \\
\hline & \multirow[t]{2}{*}{ Proteger hipóteses } & Falar pontualmente & 11 & 8 & 19 & $22,35 \%$ \\
\hline & & Estocar conexões & 0 & 0 & 0 & $0,00 \%$ \\
\hline \multicolumn{3}{|c|}{ Total Ano - Manter } & 23 & 23 & 46 & $54,12 \%$ \\
\hline Reparar & Explicar & Explicar & 2 & 0 & 2 & $2,35 \%$ \\
\hline \multicolumn{3}{|c|}{ Total Ano - Reparar } & 2 & $\mathbf{0}$ & 2 & $2,35 \%$ \\
\hline \multicolumn{3}{|c|}{ Total Categoria Cognitiva } & 43 & 42 & 85 & $100,00 \%$ \\
\hline \multicolumn{5}{|c|}{ Total Geral de Parágrafos } & \multicolumn{2}{|c|}{248} \\
\hline
\end{tabular}

Fonte: Elaborado pelos autores, conforme dados da pesquisa (2020).

Como pode ser observado na Tabela 3, houve a predominância da finalidade "manter", que apresentou um total de $54,12 \%$ dos discursos analisados nos relatórios da companhia estudada. Em seguida, destacaram-se as finalidades "ganhar" e "reparar", que estiveram presentes em respectivamente 43,53\% e 2,35\% das evidenciações. Isso indica, que a Norte Energia busca principalmente manter um apoio afirmativo ou uma simples aceitação por parte da sociedade em que está inserida.

Dentre as ações estratégicas de legitimação cognitiva utilizadas pela empresa, as que mais se destacaram foram respectivamente: "visar clareza", "falar pontualmente" e "popularizar novos modelos". Para visar clareza, a Norte Energia S.A. buscou explicar o funcionamento de determinados processos adotados por ela, conforme pode ser observado no trecho a seguir:

"Desde o início das obras, a Norte Energia desenvolve um programa específico para a destinação adequada da madeira originada da supressão vegetal. As árvores extraídas são divididas em três grupos: madeira aproveitável para serraria, resíduos grossos (raízes e galhos grossos) e resíduos finos (galhos finos e folhas das copas)” (Norte Energia, 2017, p. 50).

A Norte Energia S.A. também buscou em seus relatórios, falar pontualmente a respeito de um determinado assunto com naturalidade, comentando por exemplo, a respeito de temas como o comportamento das tartarugas-da-Amazônia, conforme pode ser observado no trecho abaixo:

"Devido ao monitoramento da Norte Energia, constatou-se que muitas das tartarugas-da-Amazônia deslocam-se por grandes distâncias. Elas saem da Ilha de Marajó e do município de Almeirim, no Pará, e da foz do Rio Negro, no Amazonas, para desovar no Tabuleiro do Embaubal. Já os tracajás são residentes da região do Xingu e reproduzem-se nas praias e nos barrancos próximos aos locais de alimentação" (Norte Energia, 2018, p. 48). 
E por fim, a Norte Energia S.A. também procurou popularizar seus novos modelos, programas ou projetos sustentáveis adotados, como pode ser observado a seguir, no trecho extraído do relatório de sustentabilidade da companhia: "O Programa de Conservação da Ictiofauna tem como principal objetivo acompanhar as alterações na estrutura da ictiofauna, bem como na atividade pesqueira no rio Xingu em decorrência das obras de construção e da operação da UHE Belo Monte" (Norte Energia, 2018, p. 49).

\subsubsection{Categorias de Legitimidade}

$\mathrm{Na}$ Tabela 4, são identificadas quais categorias de legitimidade foram utilizadas com maior frequência nos relatórios de sustentabilidade da Norte Energia S/A, durante o período abrangido pelo presente estudo:

Tabela 4 - Categorias de legitimidade

\begin{tabular}{c|c|c|c|c}
\hline Ano & Pragmática & Moral & Cognitiva & Total \\
\hline 2017 & 53 & 30 & 43 & 126 \\
2018 & 47 & 33 & 42 & 122 \\
Total & 100 & 63 & 85 & 248 \\
\% do total & $\mathbf{4 0 , 3 2 \%}$ & $\mathbf{2 5 , 4 0 \%}$ & $\mathbf{3 4 , 2 7 \%}$ & $\mathbf{1 0 0 , 0 0 \%}$ \\
\hline
\end{tabular}

Fonte: Elaborado pelos autores, conforme dados da pesquisa (2020).

Como pode ser observado na Tabela 4, a categoria de legitimidade que mais se destacou foi a "pragmática", sendo identificada em 40,32\% dos discursos analisados. Em seguida, destacaram-se as categorias “cognitiva”, com 34,27\% e a "moral”, com $25,40 \%$ das evidenciações com temas socioambientais, sendo esta última, a categoria menos utilizada pela companhia estudada.

Ao analisar estudos anteriores, também foi possível identificar, que houve resultados semelhantes aos encontrados nesta pesquisa nas publicações de Machado e Ott (2015) - que analisaram as informações ambientais das empresas que faziam parte da ISE - Índice de Sustentabilidade Empresarial - em 2013 -, Farias, Andrade e Gomes (2017) - que pesquisaram as empresas brasileiras do CDP - Carbon Disclosure Project - no período de 2006 a 2010 - e Voltarelli (2018) - que analisou as empresas que operam usinas hidrelétricas no estado do Paraná -, que apontaram a predominância da categoria de legitimidade pragmática nas divulgações de suas respectivas empresas estudadas. Desta forma, é possível inferir que a Norte Energia S.A. buscou demonstrar principalmente, que compartilha dos valores que são considerados bons pela sociedade, que ela está de acordo com os interesses da comunidade em que está inserida e que a empresa é honesta e confiável.

\subsubsection{Finalidade da Divulgação}

Na Tabela 5 são apresentadas as frequências com que cada finalidade de divulgação foi evidenciada nos relatórios de sustentabilidade da Norte Energia S.A.

Tabela 5 - Finalidade da divulgação

\begin{tabular}{c|c|c|c|c}
\hline Ano & Ganhar & Manter & Recuperar & Total \\
\hline 2017 & 85 & 38 & 3 & 126 \\
2018 & 86 & 35 & 1 & 122 \\
Total & 171 & 73 & 4 & 248 \\
\% do total & $\mathbf{6 8 , 9 5 \%}$ & $\mathbf{2 9 , 4 4 \%}$ & $\mathbf{1 , 6 1 \%}$ & $\mathbf{1 0 0 , 0 0 \%}$ \\
\hline
\end{tabular}

Fonte: Elaborado pelos autores, conforme dados da pesquisa (2020).

Quanto a finalidade da divulgação, foi possível identificar que a empresa estudada utilizou em maior parte de seus relatórios, estratégias que visam "ganhar" legitimidade, representando 68,95\% das evidenciações relacionadas a temas socioambientais. Em seguida, destacaram-se as finalidades "manter" e "recuperar", que estavam presentes respectivamente em $29,44 \%$ e $1,61 \%$ das ocorrências identificadas.

Em pesquisas anteriores, publicadas por Machado e Ott (2015), Farias, Andrade e Gomes (2017), Voltarelli e Zanchet (2017) e Voltarelli (2018), também foram identificados resultados semelhantes aos encontrados neste estudo, podendo ser observado a predominância da finalidade "ganhar", seguida das finalidades "manter" e "recuperar". Assim, é possível inferir que a empresa está buscando principalmente ganhar legitimidade organizacional, buscando através de suas ações, adequar-se as exigências da comunidade em que está inserida. 


\section{CONSIDERAÇÕES FINAIS}

Com o intuito de alcançar o objetivo geral deste estudo, que é o de analisar, baseado nas estratégias de legitimidade propostas por Suchman (1995), como a Usina Hidrelétrica de Belo Monte utiliza de relatórios de sustentabilidade para gerenciar sua legitimidade perante a sociedade, foram coletados e analisados os relatórios da Norte Energia S/A, empresa responsável pela construção e operação desta usina, referente aos anos de 2017 e 2018.

A partir das análises, percebe-se que a companhia busca ganhar legitimidade organizacional, procurando através de suas ações, adequar-se as exigências da sociedade. Além disso, também é possível inferir que a predominância das estratégias que visam ganhar legitimidade poderia ser explicada pelo fato da Usina Hidrelétrica de Belo Monte ser relativamente nova na região, fazendo assim, com que a empresa responsável por sua construção e operação ainda busque ganhar legitimidade na comunidade em que está inserida.

Também foi possível identificar, que de maneira geral não houve grandes variações nas quantidades de parágrafos identificados de cada estratégia de legitimidade entre os anos analisados neste estudo. Isso pode estar relacionado, ao fato de que os relatórios socioambientais da Norte Energia S.A. são elaborados de forma padronizada, por meio da adoção do modelo GRI e do manual da Aneel, no que diz respeito à composição de capítulos, às informações relatadas e aos métodos utilizados para a sua elaboração, o que pode ter influenciado, no tipo e na quantidade de informações divulgadas pela empresa.

Assim, espera-se que os resultados deste estudo possam contribuir para um melhor entendimento sobre as formas com que as estratégias de legitimidade são utilizadas pela empresa estudada em suas divulgações, ainda mais, por se tratar de um empreendimento relativamente novo, que gerou um grande impacto tanto para o meio ambiente, quanto para a população que reside em sua área de atuação, buscando assim, auxiliar numa melhor compreensão sobre as relações existentes entre a organização e a sociedade em que está inserida.

Como limitação do estudo, pode-se destacar a subjetividade na análise dos dados da pesquisa, pois a classificação dos trechos dos relatórios estudados, dependia da interpretação por parte do pesquisador. Para pesquisas futuras, sugere-se a realização de estudos que utilizem uma maior variedade de fontes de informações, como o site institucional, redes sociais, entre outros, para obter assim, uma visão mais ampla do que foi possível obter neste estudo, a respeito das estratégias de legitimidade utilizadas pela empresa.

\section{REFERÊNCIAS}

Beuren, I. M., Gubiani, C. A., \& Soares, M. (2013). Estratégias de legitimidade de Suchman evidenciadas nos relatórios da administração de empresas públicas do setor elétrico. Revista de Administração Pública, 47(4), p. 849-875.

Deegan, C. (2002). The legitimizing effect of social and environmental disclosures - a theoretical foundation. Accounting, Auditing \& Accountability Journal. 15(3), p. 282-311.

Deegan, C., Rankin, M., \& Tobin, J. (2002). An examination of the corporate social and environmental disclosures of BHP from 1983-1997: A testo of legítimacy theory. Accounting, Auditing \& Accountability Journal. 15(3), p. 312-343.

Dias Filho, J. M. (2007). Políticas de evidenciação contábil: Um estudo do poder preditivo e explicativo da teoria da legitimidade. Anais do EnANPAD, Rio de Janeiro, RJ, Brasil. 31.

Dias Filho, J. M. (2012). A Pesquisa Qualitativa sob a Perspectiva da Teoria da Legitimidade: uma alternativa para explicar e predizer políticas de evidenciação contábil. Interface - Revista do Centro de Ciências Sociais Aplicadas, 9(1), p. 72-86.

Eugénio, T. (2010). Avanços na divulgação de informação social e ambiental pelas empresas e a Teoria da Legitimidade. Revista Universo Contábil, 6(1), p. 102-118.

Farias, L. G. Q., Andrade, J. C. S., \& Gomes, S. M. S. (2017). Estratégias de Legitimidade de Suchman Evidenciadas pelas Empresas Brasileiras Destinatárias do Pedido do Carbon Disclosure Project. Revista de Administração de UFSM, 10(5), p. 854-869.

Feitosa, M. J., Souza, N. M., \& Gómez, C. R. (2014). Princípios da Responsabilidade Social Empresarial nas Relações "Empresa-Stakeholders" como Fonte de Vantagem Competitiva. REUNIR: Revista de Administração, Contabilidade e Sustentabilidade, 4(1), p. $42-61$.

Ferreira, F. S., Pucci, E. P., \& Lopes, D. M. (2004). Responsabilidade Social Corporativa e o uso do Balanço Social no Processo Estratégico das Organizações. Revista Alcance, 11(3), p. 359-376.

Gil, A. C. (2002). Como Elaborar Projetos de Pesquisa. (4. ed.). São Paulo: Atlas.

Luca, M. M. M., Moura, A. A. F., \& Nascimento, F. S. P. (2012). Evidenciação voluntária de informações sociais por empresas de capital aberto no Brasil com base nos indicadores de responsabilidade social da ONU. Revista Alcance, 19(3), p. 362-380.

Machado, D. P., \& Ott, E. (2015). Estratégias de legitimação social empregadas na evidenciação ambiental: Um estudo a luz da Teoria da legitimidade. Revista Universo Contábil, 11(1), p. 136-156.

Marconi, M. A., \& Lakatos, E. M. (2003). Fundamentos de Metodologia Científica. (5. ed.). São Paulo: Atlas.

Ministério do Meio Ambiente (n.d.). Uso racional dos recursos. Recuperado em: 23 março, 2019, de http://www.mma.gov.br/ responsabilidade-socioambiental/a3p/eixos-tematicos/uso-racional-do-recursos.html. 
Moreira, N. B., Dias Filho, J. M., Gomes, S. M. S., \& Conceição, M. G. (2014). Fatores que Impactam a Divulgação Voluntária de Informações Socioambientais na Percepção dos Gestores. Revista de Administração, Contabilidade e Sustentabilidade - REUNIR. 4(1), p. $62-82$.

Norte Energia. (n.d.). A história de Belo Monte - Cronologia. Recuperado em: 11 fevereiro, 2021, de https://www.norteenergiasa. com.br/pt-br/uhe-belo-monte/historico.

Norte Energia. (n.d.). Governança corporativa. Recuperado em: 7 fevereiro, 2020, de https://www.norteenergiasa.com.br/pt-br/ ri/governanca-corporativa/modelo-de-governanca.

Norte Energia. (n.d.). Norte Energia S.A. Recuperado em: 3 fevereiro, 2020, de https://www.norteenergiasa.com.br/pt-br/norte-energia.

Norte Energia. (2017). Relatório Anual e Socioambiental 2017. Recuperado em: 20 janeiro, 2020, de https://s3-sa-east-1.amazonaws.com/tcm-assets/norteenergia-pt-br/media/documents/attachments/source/20180516113723606-relatorio-anual-e-socioambiental-2017.pdf.

Norte Energia. (2018). Relatório Anual e Socioambiental 2018. Recuperado em: 20 janeiro, 2020, de https://s3-sa-east-1.amazonaws.com/tcm-assets/norteenergia-pt-br/media/documents/attachments/source/20200106171833336-Relato\%CC $\% 81$ rio $\% 20$ Anual\%20e\%20Socioambiental\%202018.pdf.

Norte Energia. (n.d.). UHE Belo Monte, a maior usina hidrelétrica 100\% brasileira. Recuperado em: 11 fevereiro, 2021, de https:// www.norteenergiasa.com.br/pt-br/uhe-belo-monte/a-usina.

O’Donovan, G. (2002). Environmental disclosures in the anual report: Extending the applicability and predictive power of legitimacy theory. Accounting, Auditing \& Accountability Journal. 15(3), p. 344-371.

Queiroz, A. R. S., \& Veiga, M. M. (2012). Análise dos impactos sociais e à saúde de grandes empreendimentos hidrelétricos: lições para uma gestão energética sustentável. Ciência e Saúde Coletiva, 17(6) p. 1387-1398.

Raupp, F. M., \& Beuren, I. M. (2006). Como elaborar trabalhos monográficos em contabilidade: teoria e prática. São Paulo: Atlas.

Rocha, T., \& Goldschmidt, A. (2010). Gestão dos Stakeholders: Como gerenciar o relacionamento e a comunicação entre a empresa e seus públicos de interesse. São Paulo: Saraiva.

Shocker, A. D., \& Sethi, S. P. (1973). An Approach to Incorporating Societal Preferences in Developing Corporate Action Strategies. California Management Review. 15(4), p. 97-105.

Suchman, M. C. (1995). Managing Legítimacy: Strategic and Institutional Approaches. The Academy of Management Review, 20(3), p. 571-610.

Voltarelli, F. R., \& Zanchet, A. (2017). Divulgação de Informações Sociais e Ambientais pela Itaipu Binacional: Um estudo sob a ótica da Teoria da Legitimidade. Revista de Contabilidade da UFBA, 11(3), p. 04-30.

Voltarelli, F. R. (2018). A percepção dos gestores sobre as contribuições da divulgação voluntária para Legitimidade Organizacional. Dissertação de Mestrado em Contabilidade, Universidade Estadual do Oeste do Paraná, Cascavel, PR, Brasil. 